The Journal of Laryngology \&amp; Otology

http://journals.cambridge.org/JLO

Additional services for The Journal of Laryngology \&amp; Otology:

Email alerts: $\underline{\text { Click here }}$

Subscriptions: $\underline{\text { Click here }}$

Commercial reprints: Click here

Terms of use : $\underline{\text { Click here }}$

\title{
Intranasal lysine-aspirin administration decreases polyp volume in patients with aspirin-intolerant asthma
}

N Ogata, Y Darby and G Scadding

The Journal of Laryngology \& Otology / Volume 121 / Issue 12 / December 2007, pp 1156 - 1160

DOI: 10.1017/S0022215107000515, Published online: 15 August 2007

Link to this article: http://journals.cambridge.org/abstract_S0022215107000515

How to cite this article:

N Ogata, Y Darby and G Scadding (2007). Intranasal lysine-aspirin administration decreases polyp volume in patients with aspirin-intolerant asthma. The Journal of Laryngology \& Otology, 121, pp 1156-1160 doi:10.1017/S0022215107000515

Request Permissions : $\underline{\text { Click here }}$ 


\title{
Intranasal lysine-aspirin administration decreases polyp volume in patients with aspirin-intolerant asthma
}

\author{
N OGATA*†, Y Darby*, G ScAdDING*
}

\begin{abstract}
Introduction: Nasal polyposis associated with aspirin-intolerant asthma tends to be difficult to control, with frequent recurrences. We examined the effect of intranasal lysine-aspirin administration on resistant nasal polyps of asthmatic, aspirin-intolerant patients, when used in addition to routine therapy.

Patients and methods: Thirteen patients with asthma and intolerance to aspirin were recruited. All but one had undergone numerous polypectomies and were uncontrolled on standard therapy with intranasal corticosteroids, leukotriene receptor antagonists and nasal douching. Aspirin treatment involved one drop $(100 \mu \mathrm{l})$ of $30 \mathrm{mg} / \mathrm{ml}$ lysine-aspirin solution to each nostril, initially daily, increased every two or three days up to a maximal of 18 drops (54 mg lysine-aspirin) a day. Nasal symptoms, nitric oxide level, nasal inspiratory peak flow rate, peak expiratory flow rate and nasendoscopic grading were assessed prior to therapy and three months later. We also compared the change in endoscopic polyp scores during three months of lysine-aspirin administration with the changes which had occurred during the three months prior to administration (during which time other therapies had been identical).

Results: Nasal blockage symptoms tended to decrease; other nasal symptoms were unchanged. Significant changes were seen in nasal inspiratory peak flow rate $(103.3 \pm 18.9$ and $140.0 \pm 16.71$ / min before and after aspirin, respectively; $p=0.014)$, but not in peak expiratory flow rate $(438.7 \pm 33.4$ and $440.0 \pm 28.4 \mathrm{l} / \mathrm{min}$ before and after aspirin, respectively; $p=0.700)$. Nasal nitric oxide levels rose significantly (in both sides, $p=0.028$ ). Expired chest nitric oxide levels did not change. Nasal polyp scores on nasendoscopic examination were significantly reduced (right side, $p=0.027$; left side, $p=0.018)$. Compared with the preceding three months, adding intranasal lysine-aspirin application had the effect on decreasing nasal polyp volume (right side, $p=0.031$; left side, $p=0.016$ ).

Conclusion: This open study suggests that intranasal lysine-aspirin administration reduces nasal polyp volume in aspirin-intolerant patients, without any adverse affect on concomitant asthma. This was a preliminary study and should be followed by a placebo-controlled, double-blind trial.
\end{abstract}

Key words: Nasal Polyp; Aspirin; Lysine-Acetylsalicylate; Asthma

\section{Introduction}

Nasal polyposis is frequently associated with asthma and aspirin intolerance. ${ }^{1}$ Although intensive treatment is usually undertaken in these patients, including topical and/or systemic steroids and endoscopic surgery, the recurrence rate is high. Polyps in these patients are more troublesome, compared with those in aspirin-tolerant patients. ${ }^{2,3}$

The underlying mechanisms of aspirin-intolerance appear to be related to inhibition of cyclo-oxygenase with subsequent release of leukotrienes and other mediators. ${ }^{4}$ Our previous study, using the leukotriene $\mathrm{D}_{4}$ receptor antagonist montelukast, confirmed the evidence that leukotrienes play an important role in the development of nasal polyps in patients with aspirin-intolerant asthma. ${ }^{5}$

Trials of desensitisation, using aspirin, have been reported in patients with aspirin-intolerant asthma. Initially, the effect on asthma of oral desensitisation was examined. ${ }^{6}$ Research then proceeded to investigate the nasal polyps of patients with aspirin-intolerant asthma, demonstrating an improvement in the clinical course. ${ }^{7,8}$ Recently, attention has focussed on intranasal administration of lysine-aspirin, the only soluble form of aspirin. Sousa et al. demonstrated that lysine-aspirin

From the *Department of Rhinology, Royal National Throat, Nose and Ear Hospital, London, UK, and the $\dagger$ Department of Otolaryngology, Kumamoto Medical Center, Kumamoto, Japan. Accepted for publication: 5 June 2007. 
reduces the numbers of cysteinyl leukotriene receptors which are up-regulated in aspirin-intolerant polyps. ${ }^{9}$ In that study, lysine-aspirin was used as monotherapy and there was no evidence of clinical benefit. $^{10}$

In this study, we examined the effect of intranasal lysine-aspirin administration on polyps in patients with aspirin-intolerant asthma, when used in addition to their routine therapy.

\section{Materials and methods}

Thirteen patients ( five men and eight women; mean age \pm standard deviation (SD) $44.5 \pm 9.3$ years) with asthma and intolerance to aspirin were recruited from the patients of the rhinology clinics of the Royal National Throat, Nose and Ear Hospital. All the patients were refractory to medical therapy with topical and/or systemic steroids, leukotriene receptor antagonists and nasal douching. In addition, all were receiving asthma therapy with inhaled corticosteroids and long-acting $\beta$ agonists. All but one patient had undergone endoscopic polypectomy; patients' mean number of operations \pm SD was $5.9 \pm 7.0$. Aspirin sensitivity was deduced from patients' histories and confirmed by lysine-aspirin nasal provocation, as previously described. ${ }^{5}$ All patients also underwent skin prick tests with 10 common, inhaled allergens. Seven patients had positive reactions to house dust mite, pollen, grass, tree or cat antigens.

Aspirin (acetylsalicylic acid) treatment was as follows. Initially, one drop $(100 \mu \mathrm{l})$ of $30 \mathrm{mg} / \mathrm{ml}$ lysine-aspirin solution per nostril was administered in the laboratory. Patients were then sent home with sachets and instructions to make up the lysine-aspirin freshly each day and to gradually increase the number of drops each side every two to three days, to a maximum of nine drops, i.e. a maximal dose of 18 drops a day, equivalent to $54 \mathrm{mg}$ of lysine-aspirin. Patients continued to take their usual intranasal steroids and/or leukotriene receptor antagonist during aspirin administration.

The following parameters were assessed before intranasal lysine-aspirin administration: nasal symptoms (via symptom questionnaires), nitric oxide level, nasal inspiratory peak flow rate, peak expiratory flow rate and nasendoscopic grading. After at least three months, these parameters were reassessed and compared with the earlier results. Twelve of the 13 patients underwent final assessment. One patient ceased treatment because of nasal pain.

Changes in patients' nasal polyp scores following lysine-aspirin administration were also compared with those during the three months prior to administration, during which time therapy, other than lysine-aspirin, had been identical.

\section{Symptom score}

A visual analogue scale of 0 to $10 \mathrm{~cm}$ was used to assess sneezing, itchiness, nasal blockage and nasal discharge.
Nasal inspiratory peak flow

Nasal inspiratory peak flow was assessed as previously described, ${ }^{11}$ in triplicate, using a nasal inspiratory peak flow meter, with the best of three values being recorded.

\section{Peak expiratory flow}

Peak expiratory flow was also assessed in triplicate, with the best of three values being recorded.

\section{Nitric oxide}

Nitric oxide levels were assessed by chemiluminescence, using the Logan-Sinclair analyser (Logan Research, Rochester, UK). Recordings were made from both sides of the nose and from the lower respiratory tract, according to European guidelines. ${ }^{12}$

\section{Nasendoscopy}

The Lund and Mackay endoscopic scoring system was applied, with minor variations. ${ }^{13}$ Polyps were classified into seven grades: $0.0,0.5,1.0,1.5,2.0,2.5$ and 3.0. Polyps in the right and left nasal cavities were evaluated and compared separately.

\section{Statistical analysis}

A one-tailed Wilcoxon matched pairs signed rank test was used to analyse data within the groups. $P$ values below 0.05 were regarded as significant. Applicable data were expressed as mean \pm standard error of the mean.

\section{Results and analysis}

\section{Symptoms}

Initial administration of $100 \mu l$ lysine-aspirin caused a small increase in nasal symptoms, especially blockage, commencing at one hour and lasting for several hours. Subsequent daily administration was followed by an increase in nasal symptoms for up to three weeks; thereafter, no symptomatic reaction occurred. There was no deterioration in asthma symptoms or control. One patient experienced nasal pain following each lysine-aspirin administration and stopped the treatment after two weeks.

At three months, there was a tendency towards improvement of nasal blockage (nasal blockage symptom scores were $8.45 \pm 0.53$ before and $6.94 \pm$ 0.79 after regular lysine-aspirin administration; $p=$ 0.09 ). Other symptoms were not improved by intranasal lysine-aspirin administration.

\section{Objective measurements}

Significant improvements were seen in nasal inspiratory peak flow rate $(103.3 \pm 18.9 \mathrm{l} / \mathrm{min}$ before and $140.0 \pm 16.7 \mathrm{l} / \mathrm{min}$ after intervention; $p=0.014$ ), but not in peak expiratory flow rate $(438.7 \pm 33.4$ $1 /$ min before and $440.0 \pm 28.4 \mathrm{l} / \mathrm{min}$ after intervention; $p=0.700$ ) (Figure 1).

Patients initially had low nasal nitric oxide levels, but these rose significantly following aspirin administration (for right side, $234 \pm 86.1 \mathrm{ppb}$ before and 


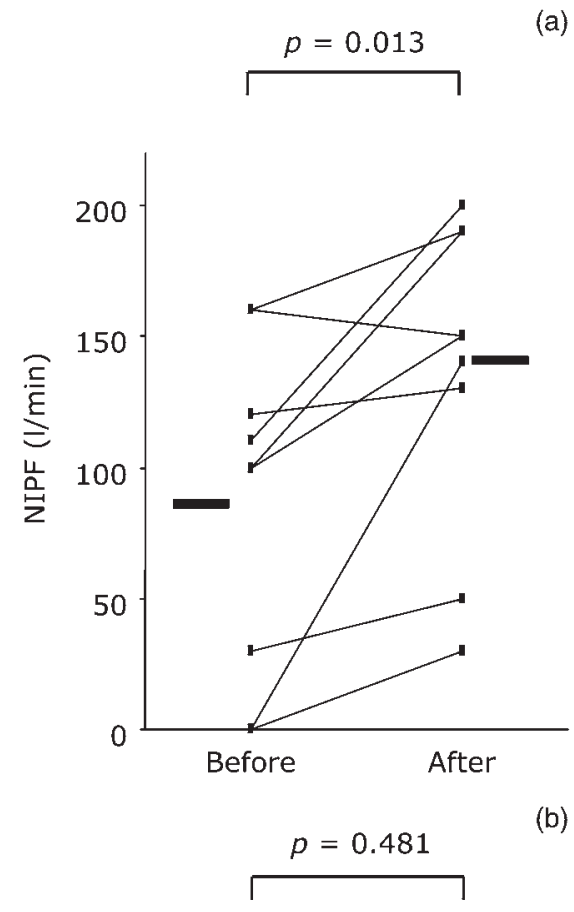

(a)

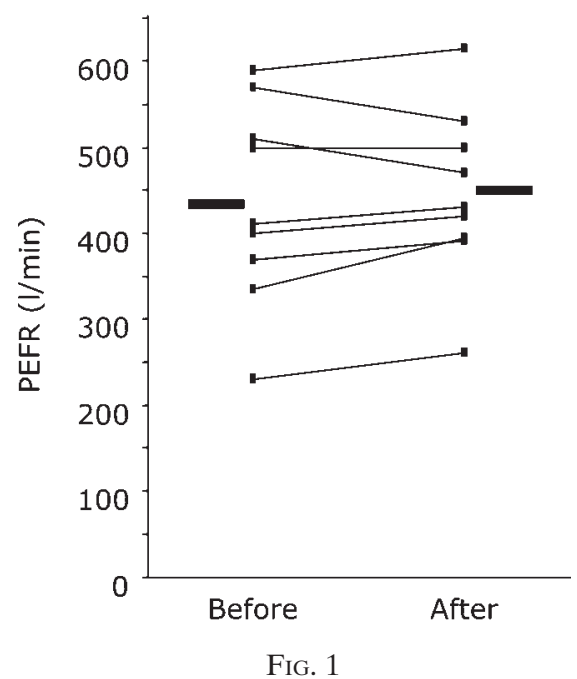

(a) Nasal inspiratory peak flow (NIPF) and (b) peak expiratory flow rate (PEFR) before and after lysine-aspirin administration in asthmatic patients with aspirin-intolerant nasal polyps. There was a significant difference in NIPF but not in PEFR. Horizontal lines indicate mean values.

$464.0 \pm 144.6 \mathrm{ppb}$ after intervention; for left side, $226.7 \pm 80.1 \mathrm{ppb}$ before and $533.0 \pm 158.8 \mathrm{ppb}$ after intervention; for both sides, $p=0.028)$. Chest nitric oxide levels did not change $(20.34 \pm 6.85 \mathrm{ppb}$ before and $18.93 \pm 4.53 \mathrm{ppb}$ after intervention; $p=0.735$ ) (Table I).

Nasendoscopic examination showed that nasal polyp grading scores on both sides were significantly reduced following lysine-aspirin administration (on right side, $1.9 \pm 0.2$ before and $1.0 \pm 0.3$ after intervention; $p=0.027$; on left side, $1.9 \pm 0.2$ before and $1.2 \pm 0.3$ after intervention; $p=0.018$ ) (Table I).

We also compared the change in endoscopic polyp grading scores after three months of lysine-aspirin administration with the changes which had occurred
TABLE I

NASAL NITRIC OXIDE LEVEL AND POLYP SCORE BEFORE AND AFTER LYSINE-ASPIRIN ADMINISTRATION

\begin{tabular}{lccc}
\hline Parameter & Before LAA & After LAA & $p$ \\
\hline Nitric oxide $(\mathrm{ppb})^{*}$ & & & \\
Nasal & & & \\
$-\mathrm{R}$ & $234.9(86.1)$ & $464.0(144.6)$ & 0.028 \\
$-\mathrm{L}$ & $226.7(80.1)$ & $533.0(158.8)$ & 0.028 \\
Chest & $20.34(6.85)$ & $18.93(4.53)$ & 0.735 \\
Nasal polyp (score) & & & \\
R & $1.9(0.2)$ & $1.0(0.3)$ & 0.027 \\
L & $1.9(0.2)$ & $1.2(0.3)$ & 0.018 \\
\hline
\end{tabular}

${ }^{*} n=7 ;{ }^{\dagger} n=10$. Data are shown as mean (standard error of the mean). $\quad \mathrm{LAA}=$ lysine-aspirin administration; $\mathrm{R}=$ right; $\mathrm{L}=$ left

during the previous three months (Figure 2). These demonstrated a significant improvement on both sides of the nose (on right, $p=0.031$; on left, $p=$ 0.016) during the lysine-aspirin treatment period, compared with the previous period, during which all other treatment had remained identical.

\section{Discussion}

Samter's triad consists of nasal polyps, asthma and aspirin intolerance. ${ }^{1}$ The inhibition of cyclo-oxygenases I and II by aspirin results in the diversion of arachidonic acid products toward the lipoxygenase pathway, resulting in overproduction of leukotrienes and other mediators, and a reduction of anti-inflammatory prostaglandin E2. This is thought to cause an exacerbation of asthma and the formation of nasal polyps. ${ }^{4}$

Intranasal therapy with lysine-aspirin has been reported to be effective in both aspirin-sensitive and aspirin-tolerant nasal polyps. ${ }^{9,14-16}$ Nucera et $a l .{ }^{15}$ showed, in an open study, that the relapse rates of nasal polyps after medical or surgical polypectomy were significantly lower than those for a non-randomised control group, in patients receiving a low (sub-desensitising) dose of lysine-aspirin once weekly. Although we previously attempted to ascertain the effects of desensitising doses of intranasal lysine-aspirin in aspirin-sensitive polyps, there was no evidence of clinical benefit when lysine-aspirin was used alone. ${ }^{10}$

In this open study, we examined the effect of lysine-aspirin administration in doses sufficient for local desensitisation, in addition to routine therapy. Our findings showed that lysine-aspirin desensitisation reduces on-going polyps. Lysine-aspirin tended to decrease nasal blockage symptoms, and this was confirmed by significant objective findings for nasal inspiratory peak flow rates, nasal nitric oxide levels and nasendoscopy scores. Significant improvement was found in nasal inspiratory peak flow rates, which supports the reported decrease in nasal blockage symptoms. Nasendoscopic examination showed that nasal polyps were significantly reduced by lysine-aspirin administration. In our study, lysine-aspirin administration also significantly elevated nitric oxide levels in the nose; this has previously 
$p=0.031$

(a)

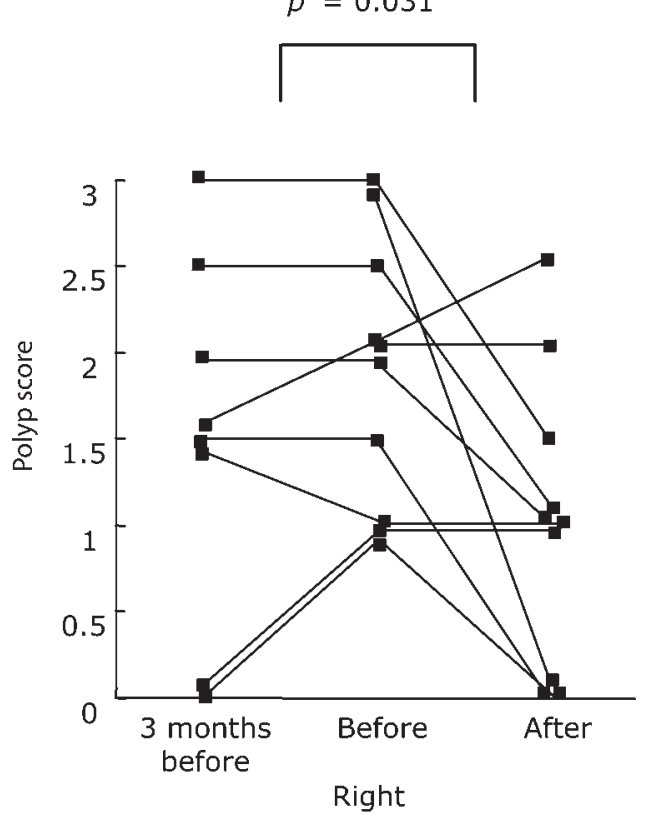

$p=0.016$

(b)

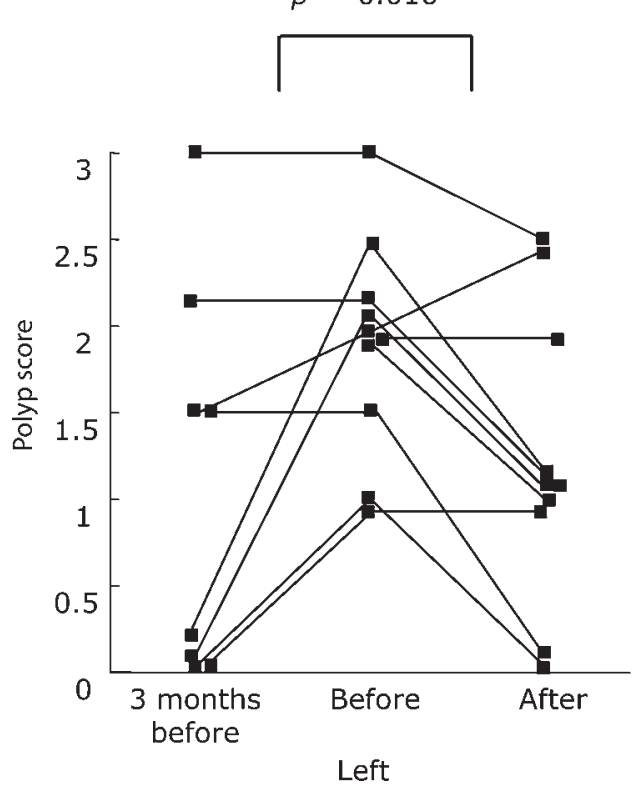

FIG. 2

(a) Right nostril and (b) left nostril changes in nasal polyp grading scores, comparing 3 months before, immediately before and 3 months after lysine-aspirin administration. There were significant score improvements for each nostril.

been shown to be associated with a reduction in polyp volume. $^{17}$ These results indicate that intranasal lysine-aspirin administration influences polyps directly.

Since we did not have a control group in this preliminary study, we compared changes in nasal polyp scores after lysine-aspirin administration with changes seen in the same patients in the previous three months. There were no differences in patients' medical therapy between the two periods, except for intranasal lysine-aspirin administration. Patients had not undergone any surgical treatment during this period. In the three months before intervention, only one nostril demonstrated any decrease in polyp size; all others were refractory to therapy. As a result of adding lysine-aspirin, a reduction of nasal polyp volume was seen in each nostril, suggesting a beneficial effect of intranasal lysine-aspirin administration.

There were no significant differences in other symptoms, such as nasal secretion, itchiness and sneezing, suggesting that lysine-aspirin does not affect basic rhinitis mechanisms.

Although the precise mechanism of aspirin desensitisation is still unclear, our previous study showed that the cysteinyl leukotriene receptors were downregulated, which may be fundamental. ${ }^{9}$ Others have pointed out a decline in the peripheral monocyte synthesis of leukotriene $\mathrm{B}_{4}$ after aspirin desensitisation. ${ }^{18}$ On the other hand, there is also evidence that the anti-proliferative effect of aspirin is the major mechanism, with aspirin having a non-specific, dose-dependent inhibitory effect on fibroblast proliferation. ${ }^{19}$

- Nasal polyposis associated with aspirin-intolerant asthma tends to be difficult to control, with frequent recurrences

- This study examined the effect of intranasal lysine-acetylsalicylate administration on resistant polyps of aspirin-intolerant patients, when used in addition to routine therapy

- This open study suggests that intranasal lysine-acetylsalicylate administration reduces polyp volume in aspirin-intolerant patients, without any adverse affect on concomitant asthma

- This is a preliminary study and should be followed by a placebo-controlled, double-blind trial

Intranasal lysine-aspirin administration did not affect lung function, as assessed by peak expiratory flow rate, and patients did not complain about any exacerbation of asthma during this trial. Side effects from gastritis, which have been reported in 20 per cent of patients undergoing oral aspirin desensitisation, were not seen in this study. ${ }^{20}$ Only one patient suffered from nasal pain, which improved on cessation of treatment.

This preliminary study should be followed by a placebo-controlled, double-blind trial.

\section{References}

1 Samter M, Beers RF. Intolerance to aspirin: clinical studies and consideration of its pathogenesis. Ann Intern Med 1968;68:875-83

2 Settipane GA, Klein DE, Settipane RJ. Nasal polyps, state of the art. Rhinology 1991;11:33-6

3 Kowalski ML. Management of aspirin-sensitive rhinosinusitis asthma syndrome: what role for aspirin desensitization? Allergy Proc 1992;13:175-84 
4 Szczeklik A, Gryglewski RJ, Czerniawska-Mysik G. Relationship of inhibition of prostaglandin biosynthesis by analgesics to asthma attacks in aspirin-sensitive patients. BMJ 1975;1:67-9

5 Ragab S, Parikh A, Darby YC, Scadding GK. An open audit of montelukast, a leukotriene receptor antagonist, in nasal polyposis associated with asthma. Clin Exp Allergy 2001;31:1385-91

6 Zeiss CR, Lockey RF. Refractory period to aspirin in a patient with aspirin-induced asthma. J Allergy Clin Immunol 1976:57:440-8

7 Berges-Gimeno MP, Simon RA, Stevenson DD. Longterm treatment with aspirin desensitization in asthmatic patients with aspirin-exacerbated respiratory disease. Allergy Clin Immunol 2003;111:180-6

8 Stevenson DD, Hankammer MA, MathisonDA, Christiansen SC, Somon RA. Aspirin desensitization treatment of aspirin-sensitive patients with rhinosinusitis-asthma: longterm outcomes. $J$ Allergy Clin Immunol 1996;98:751-8

9 Sousa AR, Parikh A, Scadding GK, Corrigan C, Lee TH. Leukotriene-receptor expression on nasal mucosal inflammatory cells in aspirin-sensitive rhinosinusitis. $N$ Engl $J$ Med 2002;347:1493-9

10 Parikh A, Scadding GK. Intranasal lysine-aspirin in aspirin-sensitive nasal polyposis: a controlled trial. Laryngoscope 2005;115:1385-90

11 Holmstrom M, Scadding GK, Lund VJ, Darby YC. Assessment of nasal obstruction: a comparison between rhinomanometry and nasal inspiratory peak flow. Rhinology 1990; 28: $191-6$

12 Kharitonov S, Alving K, Barnes PJ. Exhaled and nasal nitric oxide measurements recommendations. Eur Respir J 1997;10:1683-93

13 Lund VJ, Mackay IS. Staging in rhinosinusitis. Rhinology 1993;31:183-4

14 Patriarca G, Schiavino D, Nucera E, Papa G, Shico G, Fais G. Prevention of relapse in nasal polyposis. Lancet 1991;337: 1488
15 Nucera E, Schiavino D, Milani A, DelNinno M, Misuraca C, Buonomo A et al. Effects of lysine-acetylsalicylate (LAS) treatment in nasal polyposis: two controlled long term prospective follow up studies. Thorax 2000;55(suppl 2):S75-8

16 Scadding GK, Hassab M, Darby YC, Lund VJ, Freeman A. Intranasal lysine aspirin in recurrent nasal polyposis. Clin Otolaryngol 1995;20:561-3

17 Colantonio L, Brouillette L, Parikh A, Scadding GK. Paradoxical low nasal nitric oxide in nasal polyposis. Clin Exp Allergy 2002;32:698-701

18 Juergens UR, Christiansen SC, Stevenson DD, Zuraw BL. Inhibition of monocyte leukotriene B4 production after aspirin desensitization. J Allergy Clin Immunol 1995;96: $148-56$

19 Bruzzese N, Sica G, Iacopino F, Paludetti G, Schiavino D, Nucera $\mathrm{E}$ et al. Growth inhibition of fibroblasts from nasal polyps and normal skin by lysine acetylsalicylate. Allergy 1998;53:431-4

20 Sweet JA, Stevenson DD, Simon RA, Mathison DA. Long term effects of aspirin desensitization treatment for aspirin sensitive rhinosinusitis asthma. J Allergy Clin Immunol 1990;86:59-65

Address for correspondence:

Dr Glenis Scadding,

Royal National Throat, Nose, and Ear Hospital,

Grays Inn Road,

London WC1X 8DA, UK.

Fax: +44 2078335518

E-mail: g.scadding@ucl.ac.uk

Dr G Scadding takes responsibility for the integrity of the content of the paper.

Competing interests: None declared 